also focused attention on potential interacting partners for semaphorins and neuropilins. First, neuropilins have, rather surprisingly, been found also to be high-affinity receptors for a particular isoform of vascular endothelial cell growth factor, and to enhance binding of this ligand to its signaling receptor, the receptor tyrosine kinase KDR/Flk1 , on endothelial cells ${ }^{15}$. This has raised the interesting possibility that other receptor tyrosine kinases might function as co-receptors with neuropilins on neurons as well. In addition, a recent study has identified a novel semaphorin receptor that mediates the responses of human monocytes to two virally derived semaphorins (which are distantly related to animal semaphorins) ${ }^{16}$, and which is a member of the plexin family of transmembrane proteins ${ }^{17,18}$. Because many plexin members are expressed in the nervous system during development ${ }^{17,18}$, it will be of interest to determine whether other plexins function as co-receptors for neuropilins, or as receptors for semaphorins in the other five classes (as none of those so far tested seem to bind neuropilins $s^{2,13,19}$ ). Such studies are likely to help elucidate the complete molecular composition of class III semaphorin receptors, and thereby to pave the way for an understanding of how a semaphorin signal is transduced into the cytoskeletal changes that underlie growth-cone repulsion and collapse.

1. Tessier-Lavigne, M. \& Goodman, C. S. Science 274, 1123-1133 (1996).

2. Takahashi, T., Nakamura, F., Jin, Z., Kalb, R. G. \& Strittmatter, S. M. Nature Neurosci. 1, 487-493 (1998).

3. Kolodkin, A. L. et al. Neuron 9, 831-845 (1992).

4. Luo, Y.-L., Raible, D. \& Raper, J. A. Cell 75, 217-227 (1993).

5. Kolodkin, A. L., Matthes, D. J. \& Goodman, C. S. Cell 75, 1389-1399 (1993).

6. Mark, M. D., Lohrum, M. \& Puschel, A. W. Cell Tissue Res. 290, 299-306 (1997).
7. Messersmith, E. K. et al. Neuron 14, 949-959 (1995).

8. Taniguchi, M. et al. Neuron 19, 519-530 (1997).

9. Takagi, S. et al. Neuron 7, 295-307 (1991).

10. He, Z. \& Tessier-Lavigne, M. Cell 90, 739-751 (1997).

11. Kolodkin, A. L. et al. Cell 90, 753-762 (1997).

12. Kitsukawa, T. et al. Neuron 19, 995-1005 (1997).

13. Chen, H., Chedotal, A., He, Z., Goodman, C. S. \& Tessier-Lavigne, M. Neuron 19, 547-559 (1997).

14. Feiner, L., Koppel, A. M., Kobayashi, H. \& Raper, J. A. Neuron 19, 539-545 (1997).

15. Soker, S., Takashima, S., Miao, H. Q., Neufeld, G. \& Klagsbrun, M. Cell 92, 735-745 (1998).

16. Comeau, M. R. et al. Immunity 8, 473-482 (1998).

17. Ohta, K. et al. Neuron 14, 1189-1199 (1995).

18. Maestrini, E. Proc. Natl. Acad. Sci. USA 93, 674-678 (1996).

19. Xu, X. et al. J. Biol. Chem .273, 22428-22434 (1998).

\title{
The genetics of social behavior in worms
}

Most behaviors are thought to be controlled by multiple genes, but Mario de Bono and Cori Bargmann (University of California, San Francisco) recently reported in Cell (94, 679-689, 1998 ) that a single amino-acid substitution dramatically influences feeding behavior in the nematode C. elegans. As Randy Cassada (University of Freiburg) first noted in 1987, wild C. elegans show two distinct behavior patterns in the presence of food. Solitary strains like the N2 common lab worm (left) forage alone, slowing to half their normal speed when they encounter a food source and spreading randomly over the entire dish. In contrast, social strains like the Australian AB1 (right) travel quickly over food until they can clump together, preferentially accumulating in regions such as the border of the dish where food is abundant. When the two strains were placed together, the solitary animals still did not join clumps of social animals, indicating that their difference lies in reception rather than production of a signal.
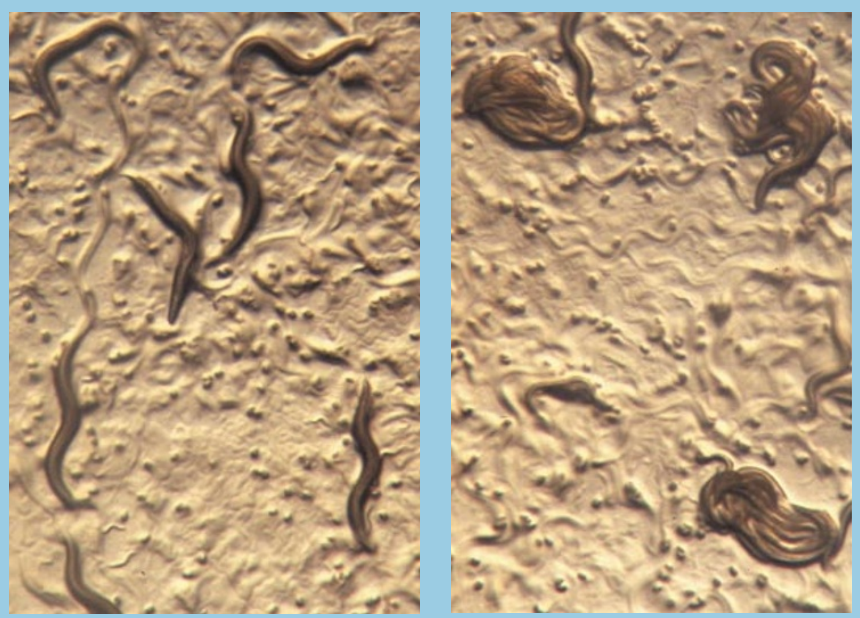

The first clue that this might be a single-gene trait was the identification of several mutant N2 animals in the laboratory that showed social feeding behavior. These recessive mutations did not complement each other, suggesting that they shared the same locus. The authors cloned this gene, called $n p r-1$, which encodes a transmembrane protein with significant homology to vertebrate neuropeptide Y receptors and is expressed in neurons. Sequencing $n p r-1$ in 12 social and 5 solitary wild strains from many areas of the world revealed that the only difference in the coding regions was that position 215 contained valine in all solitary strains and phenylalanine in all social strains. Other polymorphisms outside the $n p r-1$ locus verified that these were indeed different strains.

In rescue experiments, the solitary allele caused solitary behavior when it was injected into social animals, whereas the social allele failed to induce social behavior in solitary strains. Because only two very similar alleles were found across regions as diverse as Hawaii, Germany, Australia, England and the United States, the authors speculate that both may encode functional receptors. Residue 215 is predicted to be in the third intracellular loop of the putative receptor protein, a region that is important for G-protein coupling in other seven transmembrane receptors. This raises the possibility that the two alleles may activate different $\mathrm{G}$ proteins, although this hypothesis remains to be tested. 